\title{
Typology of patients who use emergency departments for mental and substance use disorders
}

\author{
Marie-Josée Fleury, Guy Grenier, Jean-Marie Bamvita and Francine Ferland
}

\section{Background}

Identifying profiles of people with mental and substance use disorders who use emergency departments may help guide the development of interventions more appropriate to their particular characteristics and needs.

\section{Aims \\ To develop a typology for the frequency of visits to the emer- gency department for mental health reasons based on the Andersen model.}

\section{Method}

Questionnaires were completed by patients who attended an emergency department $(n=320)$, recruited in Quebec (Canada), and administrative data were obtained related to sociodemographic/socioeconomic characteristics, mental health diagnoses including alcohol and drug use, and emergency department and mental health service utilization. A cluster analysis was performed, identifying needs, predisposing and enabling factors that differentiated subclasses of participants according to frequency of emergency department visits for mental health reasons.

\section{Results}

Four classes were identified. Class 1 comprised individuals with moderate emergency department use and low use of other health services; mostly young, economically disadvantaged males with substance use disorders. Class 2 comprised individuals with high emergency department and specialized health service use, with multiple mental and substance use disorders. Class 3 comprised middle-aged, economically advantaged females with common mental disorders, who made moderate use of emergency departments but consulted general practitioners. Class 4 comprised older individuals with multiple chronic physical illnesses co-occurring with mental disorders, who made moderate use of the emergency department, but mainly consulted general practitioners.

\section{Conclusions}

The study found heterogeneity in emergency department use for mental health reasons, as each of the four classes represented distinct needs, predisposing and enabling factors. As such, interventions should be tailored to different classes of patients who use emergency departments, based on their characteristics.

\section{Keywords}

Emergency departments; frequency of visits; mental disorders; substance use disorders; factors; cluster analysis.

\section{Copyright and usage}

(c) The Author(s) 2020. Published by Cambridge University Press on behalf of the Royal College of Psychiatrists. This is an Open Access article, distributed under the terms of the Creative Commons Attribution-NonCommercial-NoDerivatives licence (http://creativecommons.org/licenses/by-nc-nd/4.0/), which permits non-commercial re-use, distribution, and reproduction in any medium, provided the original work is unaltered and is properly cited. The written permission of Cambridge University Press must be obtained for commercial re-use or in order to create a derivative work
Since the deinstitutionalization of mental health systems, people with mental disorders (MDs), including substance use disorders (SUDs), have tended to receive treatment and follow-up in the community. ${ }^{1,2}$ However, because of efforts at cost containment, reduction of in-patient beds has not been accompanied by an adequate increase in out-patient services. ${ }^{1,3}$ From this perspective, the transformation has had adverse effects on people with mental and substance use disorders (MD-SUD) in terms of increased visits to the emergency department. ${ }^{4,5}$ For many people with MD-SUD, emergency departments provide quick access to mental health services ${ }^{6,7}$ and serve as a safety net. ${ }^{8}$ Yet providing appropriate healthcare to people with MD-SUD in the emergency department becomes a challenge when the emergency department is overloaded. ${ }^{9}$ A small proportion of people with MD-SUD also use emergency departments disproportionately for various reasons, especially for problems of access and continuity of care. ${ }^{4,10}$ Moreover, length of stay in the emergency department among people with MD-SUD is usually longer than for patients with chronic physical illnesses, ${ }^{11-13}$ because of the shortage of available in-patient beds. ${ }^{9}$ Longer stay in the emergency department may also delay access to medication and treatment, with negative effects for the health of people with MD-SUD. ${ }^{3,14}$ Service planning needs to be undertaken with a view toward reducing the frequency of emergency department visits and identifying more alternative services for individuals with MD-SUD who use the emergency department, based on a better knowledge of their characteristics and needs. ${ }^{6}$

Studies on emergency department use among people with MDSUD have focused on determinants of frequent emergency department use, generally defined as four or more visits in a given year. ${ }^{15}$ The findings of these studies may be classified in terms of needs, predisposing and enabling factors, based on the Andersen Behavioral Model, ${ }^{16}$ the main explanatory model for healthcare service use, including emergency department use in the general population, ${ }^{17}$ or among people affected by MDs and/or SUDs. ${ }^{18-20}$ Needs factors include clinical variables (e.g. diagnoses); predisposing factors include individual characteristics, such as sociodemographic variables (e.g. age, gender, education, employment and household income); and enabling factors refer to variables that facilitate access or continuity in health services, such as having a regular source of care. ${ }^{21}$

The main needs factors identified in association with higher frequency of emergency department use for mental health reasons are mental health diagnoses, including schizophrenia, ${ }^{22-24}$ personality disorder $^{22,24-28}$ and SUDs, ${ }^{4,22,23,29}$ as well as co-occurring MDSUD and/or chronic physical illnesses. ${ }^{22,30-32}$ Regarding predisposing factors, an association was found between higher frequency of emergency department use and male gender, ${ }^{1829,30}$ whereas the 
association between emergency department use and age categories was not consistent. ${ }^{29,33-37}$ Some studies have found that individuals with frequent emergency department use were more likely to have low incomes ${ }^{29,38}$ and to be unemployed. ${ }^{26,38}$ One study assessing hospital service use among people with SUDs found an association between emergency department use and lower levels of education. ${ }^{39}$ Regarding enabling factors, some studies found higher frequency of emergency department use to be associated with higher frequency of other health service use, ${ }^{26,28,40}$ including hospital admission. ${ }^{26,28}$ Yet this association was not consistent, as other studies found that the underuse of primary care or community services increased emergency department use. ${ }^{41-43}$ To the best of our knowledge, no study has attempted to identify subgroups of individuals who attend the emergency department in terms of similar needs, predisposing and enabling factors, or tested the three types of factors simultaneously. Identifying profiles of people with MD-SUD who use the emergency department may help guide the development of interventions more appropriate to their particular characteristics and needs.

Cluster analysis represents a reliable method for identifying subgroups of patients based on multiple variables. ${ }^{44}$ Cluster analysis has been used to identify several types of profiles among people with MD-SUD who use diverse health services; for example, patients admitted to hospital for the first time, ${ }^{45}$ patients who frequently use in-patient mental health services, ${ }^{46}$ people with schizophrenia receiving health services in the community, ${ }^{47}$ people with MDSUD treated in addiction rehabilitation centers, ${ }^{48}$ those receiving help from general mental health services, ${ }^{49}$ people who use antidepressants ${ }^{50}$ and homeless individuals with MD-SUD who use health services. ${ }^{51}$ The present study aimed to develop a typology based on the frequency of emergency department visits for MD-SUD among a sample of 320 people in Quebec (Canada).

\section{Method}

\section{Study setting}

As a result of the 2015 reform, ${ }^{52}$ Quebec healthcare services were regrouped into 13 integrated health and social services centres (IHSSCs) and nine university integrated health and social services centres (UIHSSCs). This reorganization entailed the mergers of general hospitals, local community health centres, nursing homes and other public health institutions such as addiction centres and youth centres, located in each of the 22 networks. Contrary to IHSSCs, UIHSSCs offer ultra-specialized tertiary care and house research centres with a teaching mandate. The IHSSCs and UIHSSCs also provide both specialized mental health services through psychiatric departments of general hospitals or mental health university institutes and primary care services located in the local community health centres of their respective health networks.

The study was conducted at six emergency departments located in four Quebec health networks selected for their diversity in terms of type of territory (urban, semi-urban), population sociodemographic characteristics and services offered. Four of the six emergency departments were psychiatric emergency departments within a general hospital, and two included addiction liaison teams. Another was a single psychiatric emergency department located in a mental health university institute, and the sixth was a general emergency department with on-site psychiatric consultants and an addiction liaison team. One of the four psychiatric emergency departments as well as the emergency department in the mental health university institute were in two networks within the Quebec metropolitan area. The first network served a population of 426760 , with mental health services provided at an IUSHSC located in the south-west sector; the second network served a population of 357500 and offered mental healthcare at a northwest IUSHSC. The three other psychiatric emergency departments were in a single network serving a population of 729997 , with mental health services provided by an IUSHC located in the provincial capital. The fourth network served 527200 inhabitants and in an outlying region near the metropolis, with mental health services dispensed by an IHSSC. Each local network also featured medical clinics, psychologists working in private practice, crisis and suicide prevention centres and other community organizations offering primary care services (e.g. self-help groups, supported employment and housing services). The IUSHC and IHSSC within each network promoted collaboration between these partners and the emergency department.

\section{Data collection}

Study recruitment took place from January to June 2017. An advisory committee consisting of decision makers from the six selected emergency departments was established to help with recruitment, validate instruments and support data collection. To better capture the occurrence of frequent overcrowding in the emergency department, recruitment was usually undertaken during peak operating hours (work hours and weekdays, Monday to Friday) as identified by decision-making partners. Interviews were conducted at emergency departments in offices designated for the study.

Participants had to be aged 18 years old or older and have made an emergency department visit for mental health reasons, as identified by emergency department triage nurses and validated through the interviews. Participants were also required to provide informed consent, as well as permission for team members to access their medical records in administrative databanks, which included diagnoses, frequency of emergency department visits and mental health service use in the 12 months before the interview. Clinical teams at the emergency department, and triage nurses especially, assisted with recruitment, evaluating patients for ability to provide consent and undergo the interview and referring them to the research team. Roughly $5 \%$ were considered ineligible for participation when at the emergency department or were unavailable because of immediate transfer to a hospital ward. Most patients who could not participate initially were interviewed at a later date, during or after their hospital stay. Written informed consent was obtained from all participants before the interview.

Participant data were collected by a structured questionnaire that required approximately 30 minutes to complete. The questionnaire covered patient sociodemographic characteristics and regular sources of healthcare (e.g. family physician, psychiatrist). Two standardized scales were included: the Alcohol Use Disorders Identification Test (AUDIT), ${ }^{53}$ measuring alcohol use and related information based on a five-point Likert scale (ten items); and the Drug Abuse Screening Test-20 (DAST-20), ${ }^{54}$ which included 20 items with yes/no responses. Patient medical records included patient diagnosis, emergency department and other medical visits as recorded by the Quebec Health Insurance Regime (Régie de l'Assurance maladie du Québec; RAMQ), and information on hospital admission, stay and discharge from the hospitalization databank (Maintenance et Exploitation des Données pour l'Étude de la Clientèle Hospitalière; MED-ECHO). All procedures performed in this study involving human participants were in accordance with the ethical standards of the institutional committee and with the 1964 Helsinki declaration and its later amendments or comparable ethical standards. Informed consent was obtained from all participants, each of whom signed a consent form. The multisite study protocol and consent form were approved by the Ethics Board of the Douglas Mental Health University Institute (IUSMD-15-36).

\section{Variables}

Variables for the study were selected based on findings from studies on emergency department use for mental health reasons, and organized under needs, predisposing and enabling factors according to 
an adapted version of the Andersen model. ${ }^{16}$ This model is very exhaustive in terms of the variables taken into account. The first version of this model was criticized, leading to gradual and substantial changes and the addition of new variables, including outcome variables such as frequency of service use. ${ }^{16}$ The Andersen model has thus increased in complexity over time with the integration of new dimensions. In this study, needs factors included diagnoses (anxiety, depression, schizophrenia, bipolar disorder, personality disorder) and number of chronic physical illnesses as recorded in the administrative databanks, as well as alcohol use disorder based on AUDIT scores of $\geq 8$, and drug use disorder based on DAST-20 scores of $\geq 6$ (scales included in the questionnaire). The decision to use a short standardized instrument to measure alcohol and drug misuse was based on the fact that these disorders are often underreported in administrative databanks, compared with other MDs, ${ }^{55}$ yet are the most frequently cited data in published emergency department studies. ${ }^{4,20,22,30}$ Predisposing factors included age, gender, education, employment and household income, based on the questionnaire. Enabling factors included having a family physician or a psychiatrist based on the questionnaire, as well as frequency of hospital admission for MD-SUD, frequency of visits to a general practitioner for MD-SUD (either family doctors or any general practitioners in walk-in clinics) and frequency of out-patient visits to a psychiatrist for MD-SUD (outside of the emergency department or hospital stay) in the previous 12 months, as recorded in the administrative databanks.

\section{Analysis}

Univariate analyses included frequency distributions for categorical variables, and mean values with s.d. for continuous variables.
Cluster analyses were performed, identifying distinctive characteristics among subsamples based on their respective differences on each variable, and identifying a typology of classes. Frequency of emergency department visits for MD-SUD reasons was the variable of interest. The number of classes was determined with the Schwarz Bayesian criterion and a goodness-of-fit model was produced. Comparison analyses were carried out for each variable to assess statistically significant differences between the classes, using $\chi^{2}$ tests for categorical variables and ANOVA $t$-tests for continuous variables.

\section{Results}

Of the 372 people who used emergency departments who were invited to participate in the study, 328 accepted, for an $88 \%$ response rate. Of these 328 participants, $172(52 \%)$ were recruited at the mental health university institute (psychiatric hospital) located in the south-west metropolitan network, 89 (27\%) were recruited at the three merged psychiatric/general emergency departments of the provincial capital network, $38(12 \%)$ were recruited at the merged psychiatric/general emergency department of the northwest metropolitan network, and 29 (9\%) were recruited at the general emergency department for the network located in the outlying region near the metropolis. Data from 320 participants were used for the analyses, as administrative data were missing for the other eight invited participants. Mean age was 39 years (Table 1), and $52 \%$ of the sample were women. Regarding household income, 44\% reported earning less than Can\$21000 per year. A small majority (56\%) had some post-secondary education, 33\%

\begin{tabular}{|c|c|c|c|c|}
\hline & & Minimum & Maximum & \\
\hline \multirow[t]{16}{*}{ Predisposing } & Age, mean (s.d.) & 17.00 & 83.00 & $38.92(13.56)$ \\
\hline & Age categories, $n(\%)$ & & & \\
\hline & 18-29 years & & & $89(27.8)$ \\
\hline & 30-44 years & & & $131(40.9)$ \\
\hline & $\geq 45$ years & & & 100 (31.3) \\
\hline & Gender, $n$ (\%) & & & \\
\hline & Female & & & $165(51.6)$ \\
\hline & Male & & & $155(48.4)$ \\
\hline & Household income, $n$ (\%) & & & \\
\hline & $<$ Can $\$ 21000 /$ year & & & $141(44.1)$ \\
\hline & $>$ Can $\$ 21000-50$ 000/year & & & $123(38.4)$ \\
\hline & $<$ Can $\$ 50$ 000/year & & & $56(17.5)$ \\
\hline & Education, $n(\%)$ & & & \\
\hline & High school & & & $141(44.1)$ \\
\hline & Post-secondary & & & $179(55.9)$ \\
\hline & Employed, $n$ (\%) & & & 107 (33.4) \\
\hline \multirow[t]{8}{*}{ Enabling } & Regular source of care, $n$ (\%) & & & \\
\hline & Has a family physician & & & $207(64.7)$ \\
\hline & Has a psychiatrist & & & $144(45.0)$ \\
\hline & Outcomes, mean (s.d.) ${ }^{a}$ & & & \\
\hline & Frequency of hospital admission for MD-SUD & 0.00 & 11.00 & $0.85(1.34)$ \\
\hline & Frequency of visits to a general practitioner for MD-SUD & 0.00 & 17 & $1.07(2.23)$ \\
\hline & Frequency of visits to a psychiatrist for MD-SUD & 0.00 & 98 & $8.06(15.28)$ \\
\hline & Frequency of visits to the emergency department for MD-SUD & 0.00 & 40.00 & $1.79(3.74)$ \\
\hline \multirow[t]{8}{*}{ Needs } & Number of chronic physical illnesses, mean (s.d.) & 0.00 & 5.00 & $0.45(0.81)$ \\
\hline & DAST-20 score $\geq 6, n(\%)$ & & & $90(28.1)$ \\
\hline & AUDIT score $\geq 8, n(\%)$ & & & $98(30.6)$ \\
\hline & Anxiety, $n(\%)$ & & & $98(30.6)$ \\
\hline & Depression, $n(\%)$ & & & $146(45.6)$ \\
\hline & Schizophrenia, $n$ (\%) & & & $95(29.7)$ \\
\hline & Bipolar disorder, $n$ (\%) & & & $60(18.8)$ \\
\hline & Personality disorder, $n$ (\%) & & & 50 (15.6) \\
\hline
\end{tabular}


reported having employment, $45 \%$ had a psychiatrist and $65 \%$ had a family physician. The mean frequency of out-patient visits to a psychiatrist in the previous 12 months was 8.06 (s.d. 15.28), whereas an average of 1.07 (s.d. 2.23) visits were made to general practitioners. The mean frequency of emergency department visits for mental health reasons was 1.79 (s.d. 3.74), and the hospital admission rate was 0.85 (s.d. 1.34; previous 12 months). The three most prevalent MDs in the sample were depression (46\%), anxiety (31\%) and schizophrenia (30\%). A total of $31 \%$ had an alcohol use disorder (AUDIT score $\geq 8$ ) and $28 \%$ had a drug use disorder (DAST-20 score $\geq 6$ ) (Table 1).

The four-class typology of participants produced by the cluster analysis is presented in Table 2, and comparison tests between classes for each variable appear in Table 3. Goodness of fit for the model was acceptable.

Class 1 participants presented with the lowest frequency of emergency department visits for MD-SUD reasons. Their frequency of visits was statistically different from that of class 2 , but not from the frequencies of the other two classes. Class 1 individuals were mostly younger, male, with only secondary education, earning less than Can $\$ 21000 /$ year and predominantly affected by alcohol use disorder. Gender, education and AUDIT scores $\geq 8$ were statistically different between class 1 and the other three classes, whereas age and household income were statistically different between class 1 and classes 3 and 4 . Class 1 participants were also significantly less affected by anxiety, depression and bipolar disorder than those in the other three classes; they had a lower incidence of schizophrenia and personality disorder relative to classes 2 and 3, and fewer chronic physical illnesses than classes 2 and 4. However, class 1 individuals were more affected by drug use disorders than classes 3 and 4 . Frequency of hospital admission for MD-SUD in class 1 was significantly lower than in classes 2 and 4 . Individuals in class 1 were statistically less likely to have a family physician, and their frequency of visits to a general practitioner was lower than that for classes 3 and 4 . Class 1 individuals were also less likely to have a psychiatrist than members of classes 2 and 4 , and they made fewer visits to a psychiatrist for reasons related to MDSUD compared with individuals in class 2 . Class 1 was labelled 'individuals with moderate emergency department use and low use of other health services; mostly young, economically disadvantaged males with substance use disorders'.

Class 2 showed the highest mean value (4.64, s.d. 7.00) on frequency of emergency department visits for MD-SUD. This result was statistically different from results for the other classes. The

Table 2 Typology of patients who use emergency departments for mental disorders and substance use disorders: two-step cluster analysis ( $N=320$ )

\begin{tabular}{|c|c|c|c|c|c|c|}
\hline & & $\begin{array}{l}\text { Class } 1 \\
(n=74 ; 23.1 \%)\end{array}$ & $\begin{array}{c}\text { Class } 2 \\
(n=66 ; 20.6 \%)\end{array}$ & $\begin{array}{c}\text { Class } 3 \\
(n=90 ; 28.1 \%)\end{array}$ & $\begin{array}{c}\text { Class } 4 \\
(n=90 ; 28.1 \%)\end{array}$ & $\begin{array}{c}\text { Combined } \\
(n=320 ; 100.0 \%)\end{array}$ \\
\hline $\begin{array}{r}\text { Variable of } \\
\text { interest }\end{array}$ & $\begin{array}{l}\text { Frequency of visits to the emergency } \\
\text { department for MD-SUD, mean (s.d.) }\end{array}$ & $0.73^{2}(1.41)$ & $4.641^{1,3,4}(7.00)$ & $1.14^{2}(1.82)$ & $1.21^{2}(1.32)$ & $1.79(3.74)$ \\
\hline \multirow{15}{*}{ Predisposing } & \multicolumn{6}{|l|}{ Age categories, $n$ (\%) } \\
\hline & $18-29$ years & 35 (39.3) & $21(23.6)$ & $30(33.7)$ & $3(3.4)$ & 89 (100.0) \\
\hline & 30-44 years & 24 (18.3) & $32(24.4)$ & $56(42.7)$ & 19 (14.5) & $131(100.0)$ \\
\hline & $\geq 45$ years & $15^{3,4}(15.0)$ & $13^{3,4}(13.0)$ & $4^{1,2}(4.0)$ & $68^{1,2}(68.0)$ & $100(100.0)$ \\
\hline & \multicolumn{6}{|l|}{ Gender, $n(\%)$} \\
\hline & Female & $12(7.3)$ & $31(18.8)$ & $67(40.6)$ & 55 (33.3) & $165(100.0)$ \\
\hline & Male & $62^{2,3,4}(40.0)$ & $35^{1,3,4}(22.6)$ & $23^{1,2,4}(14.8)$ & $35^{1,2,3}(22.6)$ & $155(100.0)$ \\
\hline & \multicolumn{6}{|l|}{ Education, $n$ (\%) } \\
\hline & High school & $46(32.6)$ & 27 (19.1) & $24(17.0)$ & 44 (31.2) & $141(100.0)$ \\
\hline & Post-secondary & $28^{2,3}(15.6)$ & $39^{1,3}(21.8)$ & $66^{1,2,4}(36.9)$ & $46^{3}(25.7)$ & $179(100.0)$ \\
\hline & Employed, $n(\%)$ & $18^{2,3}(16.8)$ & $7^{1,3}(6.5)$ & $70^{1,2,4}(65.4)$ & $12^{3}(11.2)$ & $107(100.0)$ \\
\hline & \multicolumn{6}{|l|}{ Household income, $n(\%)$} \\
\hline & $<$ Can\$21 000/year & $48(34.0)$ & $43(30.5)$ & $9(6.4)$ & $41(29.1)$ & $141(100.0)$ \\
\hline & Can\$21 000-50 000/year & 25 (20.3) & $17(13.8)$ & $52(42.3)$ & $29(23.6)$ & $123(100.0)$ \\
\hline & $>$ Can $\$ 50$ 000/year & $1^{3,4}(1.8)$ & $61^{3,4}(10.7)$ & $29^{1,2,4}(51.8)$ & $20^{1,2,4}(35.7)$ & $56(100.0)$ \\
\hline \multirow[t]{7}{*}{ Enabling } & \multicolumn{6}{|l|}{ Regular source of care, $n(\%)$} \\
\hline & Has a family physician & $22^{3,4}(10.6)$ & $29^{3,4}(14.0)$ & $77^{1,2}(37.2)$ & $79^{1,2}(38.2)$ & $207(100.0)$ \\
\hline & Has a psychiatrist & $20^{2,4}(13.9)$ & $59^{1,3,4}(41.0)$ & $2^{1,2}(18.8)$ & $38^{1,2}(26.4)$ & $144(100.0)$ \\
\hline & \multicolumn{6}{|l|}{ Outcomes, mean (s.d.) } \\
\hline & $\begin{array}{l}\text { Frequency of hospital admission for } \\
\text { MD-SUD }\end{array}$ & $0.36^{2,4}(0.61)$ & $2.11^{1,3,4}(2.08)$ & $0.47^{2}(0.89)$ & $0.71^{1,2}(0.78)$ & $0.85(1.34)$ \\
\hline & $\begin{array}{l}\text { Frequency of visits to a general } \\
\text { practitioner for MD-SUD }\end{array}$ & $0.24^{3,4}(0.77)$ & $0.61^{3}(1.29)$ & $1.86^{1,2}(3.11)$ & $1.30^{1}(2.24)$ & $1.07(2.23)$ \\
\hline & $\begin{array}{l}\text { Frequency of visits to a psychiatrist for } \\
\text { MD-SUD }\end{array}$ & $4.07^{2}(10.53)$ & $22.26^{1,3}(22.67)$ & $2.21^{2,4}(4.49)$ & $6.77^{2,3}(12.30)$ & $8.06(15.28)$ \\
\hline \multirow[t]{8}{*}{ Needs } & $\begin{array}{l}\text { Number of chronic physical illnesses, mean } \\
\text { (s.d.) }\end{array}$ & $0.16^{4}(0.41)$ & $0.48(0.92)$ & $0.24^{4}(0.50)$ & $0.86^{1,3}(1.02)$ & $0.45(0.81)$ \\
\hline & DAST-20 score $\geq 6, n(\%)$ & $31^{3,4}(34.4)$ & $34^{3,4}(37.8)$ & $19^{1,2,4}(21.1)$ & $6^{1,2,3}(6.7)$ & $90(100.0)$ \\
\hline & AUDIT score $\geq 8, n(\%)$ & $41^{2,3,4}(41.8)$ & $23^{1,4}(23.5)$ & $27^{1,4}(27.6)$ & $7^{1,2,3}(7.1)$ & $98(100.0)$ \\
\hline & Anxiety, $n(\%)$ & $0^{2,3,4}(0.0)$ & $32^{1,4}(32.7)$ & $37^{1}(37.8)$ & $29^{1,2}(29.6)$ & $98(100.0)$ \\
\hline & Depression, $n(\%)$ & $1^{2,3,4}(0.7)$ & $56^{1,3,4}(38.4)$ & $47^{1,2}(32.2)$ & $42^{1,2}(28.8)$ & $146(100.0)$ \\
\hline & Schizophrenia, $n$ (\%) & $23^{2,3}(24.2)$ & $32^{1,3}(33.7)$ & $7^{1,2,4}(7.4)$ & $33^{3}(34.7)$ & 95 (100.0) \\
\hline & Bipolar disorder, $n$ (\%) & $1^{2,3,4}(1.7)$ & $24^{1,3}(40.0)$ & $12^{1,2,4}(20.0)$ & $23^{1,3}(38.3)$ & $60(100.0)$ \\
\hline & Personality disorder, $n$ (\%) & $4^{2,3}(8.0)$ & $18^{1,4}(36.0)$ & $16^{1}(32.0)$ & $12^{2}(24.0)$ & $50(100.0)$ \\
\hline \multicolumn{7}{|c|}{$\begin{array}{l}\text { The number in superscript indicates with which class the variable is significantly different. Class 1: individuals with moderate emergency department use and low use of other health } \\
\text { services; mostly young, economically disadvantaged males with substance use disorders. Class 2: individuals with high emergency department and specialized health service use, with } \\
\text { multiple MD-SUD. Class 3: Middle-aged, economically advantaged females with common mental disorders, who made moderate use of emergency departments but consulted general } \\
\text { practitioners. Class 4: Older individuals with multiple chronic physical illnesses co-occurring with mental disorders, who made moderate use of the emergency department, but mainly } \\
\text { consulted general practitioners. } \\
\text { MD-SUD, mental and substance use disorders; DAST-20, Drug Abuse screening Test-20; AUDIT, Alcohol Use Disorders Identification Test. } \\
\text { a. In the previous } 12 \text { months. }\end{array}$} \\
\hline
\end{tabular}




\begin{tabular}{|c|c|c|c|c|c|c|c|c|}
\hline & & $\begin{array}{c}\text { Total } \\
\text { sample }\end{array}$ & $\begin{array}{c}\text { Class } 1 \\
\text { versus } 2\end{array}$ & $\begin{array}{c}\text { Class } 1 \\
\text { versus } 3\end{array}$ & $\begin{array}{c}\text { Class } 1 \\
\text { versus } 4\end{array}$ & $\begin{array}{c}\text { Class } 2 \\
\text { versus } 3\end{array}$ & $\begin{array}{c}\text { Class } 2 \\
\text { versus } 4\end{array}$ & $\begin{array}{c}\text { Class } 3 \\
\text { versus } 4\end{array}$ \\
\hline & & $P$-value & $P$-value & $P$-value & $P$-value & $P$-value & $P$-value & $P$-value \\
\hline $\begin{array}{r}\text { Variable of } \\
\text { interest }\end{array}$ & $\begin{array}{l}\text { Frequency of visits to the emergency } \\
\text { department for MD-SUD }\end{array}$ & $<0.0001^{\mathrm{C}}$ & $<0.0001^{\mathrm{C}}$ & $0.476^{c}$ & $0.149^{C}$ & $0.001^{c}$ & $0.001^{c}$ & $1.000^{c}$ \\
\hline \multirow[t]{5}{*}{ Predisposing } & Age categories & $<0.0001^{\mathrm{a}}$ & $0.114^{\mathrm{a}}$ & $<0.0001^{a}$ & $<0.0001^{a}$ & $0.009^{a}$ & $<0.0001^{\mathrm{a}}$ & $<0.0001^{a}$ \\
\hline & Gender & $<0.0001^{a}$ & $<0.0001^{a}$ & $<0.0001^{a}$ & $<0.0001^{a}$ & $<0.0001^{a}$ & $0.079^{\mathrm{a}}$ & $0.056^{\mathrm{a}}$ \\
\hline & Education & $<0.0001^{a}$ & $0.001^{a}$ & $<0.0001^{a}$ & $0.026^{a}$ & $0.024^{a}$ & $0.471^{a}$ & $0.003^{a}$ \\
\hline & Employed & $<0.0001^{\mathrm{a}}$ & $0.034^{a}$ & $<0.0001^{\mathrm{a}}$ & $0.070^{\mathrm{a}}$ & $<0.0001^{\mathrm{a}}$ & $0.607^{\mathrm{a}}$ & $<0.0001^{a}$ \\
\hline & Household income & $<0.0001^{\mathrm{a}}$ & $0.165^{\mathrm{a}}$ & $<0.0001^{\mathrm{a}}$ & $0.003^{a}$ & $<0.0001^{\mathrm{a}}$ & $0.047^{\mathrm{a}}$ & $<0.0001^{a}$ \\
\hline \multirow[t]{5}{*}{ Enabling } & Has a family physician & $<0.0001^{a}$ & $0.081^{a}$ & $<0.0001^{a}$ & $<0.0001^{a}$ & $<0.0001^{a}$ & $<0.0001^{a}$ & $0.661^{a}$ \\
\hline & Has a psychiatrist & $<0.0001^{a}$ & $<0.0001^{a}$ & $0.675^{\mathrm{a}}$ & $0.043^{\mathrm{a}}$ & $<0.0001^{\mathrm{a}}$ & $<0.0001^{a}$ & $0.088^{\mathrm{a}}$ \\
\hline & $\begin{array}{l}\text { Frequency of hospital admission for } \\
\text { MD-SUD }\end{array}$ & $<0.0001^{\mathrm{C}}$ & $<0.0001^{\mathrm{C}}$ & $0.947^{c}$ & $0.010^{c}$ & $<0.0001^{\mathrm{C}}$ & $<0.0001^{\mathrm{C}}$ & $0.274^{c}$ \\
\hline & $\begin{array}{l}\text { Frequency of visits to a general } \\
\text { practitioner for MD-SUD }\end{array}$ & $<0.0001^{\mathrm{C}}$ & $0.261^{c}$ & $<0.0001^{c}$ & $<0.0001^{\mathrm{c}}$ & $0.005^{c}$ & $0.092^{\mathrm{C}}$ & $0.676^{\mathrm{C}}$ \\
\hline & $\begin{array}{l}\text { Frequency of visits to a psychiatrist for } \\
\text { MD-SUD }\end{array}$ & $<0.0001^{\mathrm{C}}$ & $<0.0001^{\mathrm{c}}$ & $0.650^{\mathrm{C}}$ & $0.573^{c}$ & $<0.0001^{\mathrm{C}}$ & $<0.0001^{\mathrm{C}}$ & $0.008^{c}$ \\
\hline \multirow[t]{8}{*}{ Needs } & Number of chronic physical illnesses & $<0.0001^{\mathrm{C}}$ & $0.057^{c}$ & $0.820^{C}$ & $<0.0001^{\mathrm{C}}$ & $0.295^{C}$ & $0.107^{C}$ & $<0.0001^{\mathrm{C}}$ \\
\hline & DAST-20 score $\geq 6$ & $<0.0001^{a}$ & $0.254^{\mathrm{a}}$ & $0.004^{\mathrm{a}}$ & $<0.0001^{a}$ & $<0.0001^{a}$ & $<0.0001^{a}$ & $0.005^{\mathrm{a}}$ \\
\hline & AUDIT score $\geq 8$ & $<0.0001^{a}$ & $0.015^{\mathrm{a}}$ & $0.001^{\mathrm{a}}$ & $<0.0001^{a}$ & $0.521^{a}$ & $<0.0001^{a}$ & $<0.0001^{a}$ \\
\hline & Anxiety & $<0.0001^{a}$ & $<0.0001^{b}$ & $<0.0001^{b}$ & $<0.0001^{b}$ & $0.360^{\mathrm{a}}$ & $0.040^{\mathrm{a}}$ & $0.216^{\mathrm{a}}$ \\
\hline & Depression & $<0.0001^{a}$ & $<0.0001^{b}$ & $<0.0001^{b}$ & $<0.0001^{b}$ & $<0.0001^{a}$ & $<0.0001^{a}$ & $0.456^{\mathrm{a}}$ \\
\hline & Schizophrenia & $<0.0001^{a}$ & $0.035^{\mathrm{a}}$ & $<0.0001^{\mathrm{a}}$ & $0.453^{a}$ & $<0.0001^{\mathrm{a}}$ & $0.139^{a}$ & $<0.0001^{a}$ \\
\hline & Bipolar disorder & $<0.0001^{a}$ & $<0.0001^{b}$ & $0.007^{\mathrm{b}}$ & $<0.0001^{\text {b }}$ & $0.001^{a}$ & $0.146^{\mathrm{a}}$ & $0.038^{\mathrm{a}}$ \\
\hline & Personality disorder & $0.004^{a}$ & $<0.0001^{b}$ & $0.017^{b}$ & $0.115^{\mathrm{b}}$ & $0.156^{a}$ & $0.029^{\mathrm{a}}$ & $0.411^{\mathrm{a}}$ \\
\hline $\begin{array}{l}\text { MD-SUD, mental } \\
\text { a. Pearson } \chi^{2} \text {-tes } \\
\text { b. Fisher exact te } \\
\text { c. ANOVA } t \text {-test. }\end{array}$ & abstance use disorders; DAST-20, Drug Abu & & DIT & 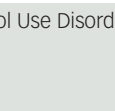 & & & & \\
\hline
\end{tabular}

salient features of class 2 were highest values on frequency of hospital admission for MD-SUD, having a psychiatrist, frequency of visits to a psychiatrist for MD-SUD, depression, DAST-20 score of $\geq 6$, bipolar disorder and personality disorder. The first four variables were statistically different compared with those from the other three classes. The DAST-20 score for class 2 was statistically different from scores for classes 3 and 4; the score on bipolar disorder was statistically different between class 2 and classes 1 and 3, whereas scores on personality disorder were statistically different between class 2 and classes 1 and 4 . Individuals in class 2 were also significantly more affected by anxiety and alcohol use disorders compared with individuals in classes 1 and 4, and they registered higher rates of schizophrenia compared with the rates for classes 1 and 3. Class 2 was labelled 'individuals with high emergency department and specialized health service use, with multiple MD-SUD'.

Both remaining classes ( 3 and 4 ) had intermediary values on frequency of emergency department visits for MD-SUD and were not statistically different in this regard from class 1 participants. Also, significantly more individuals in these two classes had a family physician compared with individuals in classes 1 and 2. However, classes 3 and 4 differed in terms of other characteristics.

Class 3 individuals were different than members of the other three classes, tending to be middle-aged, female, more highly educated, employed and have a higher household income, as well as relatively less affected by schizophrenia. Statistical differences were found on all these variables between class 3 and the other classes. The frequency of visits to a psychiatrist for MD-SUD was significantly lower in class 3 than in classes 2 and 4 . Yet class 3 individuals were significantly more affected by depression than members of classes 1 and 2 , and more affected by anxiety relative to class 1 . Class 3 was labelled 'middle-aged, economically advantaged females with common MDs, who made moderate use of emergency departments but consulted general practitioners'.

Compared with the other three classes, individuals in class 4 were older, and had the highest number of chronic physical illnesses. They were also significantly more affected by bipolar disorder than individuals in classes 1 and 3, and were more affected by schizophrenia than those in class 3. However, they showed significantly less alcohol or drug involvement than individuals in the other classes. Class 4 was labelled 'older individuals with multiple chronic physical illnesses co-occurring with MDs, who made moderate use of the emergency department, but mainly consulted general practitioners'.

\section{Discussion}

This study developed a typology of individuals who use the emergency department for MD-SUD reasons based on the Andersen model. Cluster analysis identified four classes, each one associated with specific needs, predisposing or enabling factors. One class comprised individuals with high emergency department use (class 2), whereas the three other classes comprised individuals with moderate emergency department use. Class 2 was the smallest, accounting for $21 \%$ of the sample, which confirms earlier findings showing that individuals with frequent emergency department use with MD-SUD account for 0.03 to $18 \%$ of study samples. ${ }^{56}$ Moreover, the frequency of individuals with high emergency department use in class 2 was quite similar to that for the general Quebec population (17\%), according to administrative data. ${ }^{57}$

Some classes identified in our study show similarities with those of previous studies that assessed very distinct samples of people with MD-SUD. For example, one study of 4526 individuals receiving services from an addiction rehabilitation center ${ }^{48}$ identified a class of individuals with multiple MDs and SUDs and high emergency department use that bore some resemblance to our class 2. Another study of 406 individuals who experienced at least one episode of $\mathrm{MD}^{58}$ identified a subclass of middle-aged females with high income, depressive disorders and moderate health services that looked quite similar to our class 3 . 
Each of the four classes exhibited very marked differences in terms of needs factors: SUDs for class 1, multiple MD-SUD for class 2, common MDs for class 3 and chronic physical illnesses (co-occurring with MDs) for class 4. Differences among the classes emerged in terms of enabling factors: class 2 individuals were more likely to have a psychiatrist and had greater frequencies of hospital admission and visits to a psychiatrist for MD-SUD, whereas members of classes 3 and 4 were more likely to have a family physician and make use of this service. By contrast, class 1 individuals used fewer health services overall. In terms of predisposing factors, important differences were also found in age categories (younger in class 1, middle-aged in class 3 and older in class 4 ), gender (male in class 1 , female in class 3 ), education (less education in class 1 , more education in class 3 ), employment (much more prevalent in class 3 versus other classes) and household income (higher in class 3, lower in classes 1 and 2).

The characteristics of class 2 resembled findings reported in the literature for individuals with high emergency department use with MD-SUD. Individuals with multiple co-occurring MDs and SUDs, similar to our class 2 , were more likely to have high emergency department use. ${ }^{22,32,56}$ Studies also found associations between high emergency department use and specific diagnoses, such as schizophrenia, ${ }^{22-24}$ bipolar disorder, ${ }^{33}$ depression, ${ }^{33,59}$ personality disorder, ${ }^{22,25,26,28}$ anxiety ${ }^{23,24,26,33}$ and alcohol and drug use disorders. ${ }^{4,22,23,29}$ Moreover, individuals from class 2 were frequently admitted to hospital and made more frequent visits to psychiatrists than others (enabling factors). Previous studies have also found associations between high emergency department use and high frequency use of other health services. ${ }^{20,26,28,40,60}$ However, few individuals from class 2 had a family physician and their frequency of visits to a general practitioner for MD-SUD was low. Because general practitioners tend to lack confidence in their ability to deal with people affected by multiple MD-SUD, ${ }^{61}$ it is possible that class 2 individuals had difficulty finding a general practitioner who would take them on. Finally, although previous studies found associations between frequent emergency department use and predisposing factors such as male gender ${ }^{29,30}$ and younger age ${ }^{34,35}$ or older age, ${ }^{36}$ individuals from class 2 were not characterized by specific predisposing factors that could distinguish them from other classes.

The class that made the least use of emergency departments for MD-SUD reasons (class 1) differed from class 2 in most areas of needs (AUDIT score, anxiety, depression, schizophrenia, bipolar disorders, personality disorder), predisposing (gender, education, employment), and enabling factors (has a psychiatrist, frequency of visits to a psychiatrist, frequency of hospital admission for MD-SUD). Unlike in class 2, the prevalence of MDs was very low among class 1 individuals, which may explain both their lower frequency of emergency department use and hospital admission, and fewer visits to a psychiatrist. Compared with class 2, class 1 registered more alcohol and drug use disorders. The presence of this clientele in the emergency department is perhaps related to the indirect effects of alcohol or drug intoxication, such as accidents or assaults, ${ }^{62}$ e.g. after an episode of binge drinking. ${ }^{63}$ Population studies have also found that individuals affected by SUDs exclusively use fewer mental health services compared with those affected by co-occurring MD-SUD. ${ }^{64,65}$ This underutilization of services may also be because of the stigmatization of this clientele by health professionals, ${ }^{66}$ prompting some to use the emergency department. Moreover, class 1 mainly comprised young men with low income, low education and high unemployment. Individuals in such circumstances are generally more reluctant to use health services, barring serious threats to health that may incite them to use the emergency department. ${ }^{67}$

Class 3, which included individuals with moderate emergency department use, also differed from class 2 in terms of all predisposing and enabling factors, and several needs factors (drug use disorders, depression, schizophrenia and bipolar disorder). Regarding predisposing factors, individuals from class 3 showed several characteristics negatively associated with frequent emergency department use, such as female gender, ${ }^{18,29,30}$ younger and middle age ${ }^{34-36}$ and economic advantage. ${ }^{22,29}$ Moreover, in terms of needs, class 3 individuals were mainly affected by common MDs (depression, anxiety), but relatively less affected by serious MDs or SUDs. Patients with such characteristics were also more likely to use primary care services, notably general practitioners. Yet even in this class, the mean frequency of visits to a general practitioner over the previous 12 months (1.86; s.d. 3.11) was low, below the recommended rates (four consultations per year) for follow-up of MDs. ${ }^{68}$

Class 4 differed from class 2 mainly in terms of needs factors (alcohol and drug use disorders, anxiety, depression and personality disorder) followed by enabling factors (has a family physician, has a psychiatrist, frequency of hospital admission for MD-SUD, frequency of visits to a psychiatrist for MD-SUD) and predisposing factors (age, household income). Concerning needs factors, the very low prevalence of both alcohol and drug use disorders in class 4 was astonishing. One explanation may be greater abstinence among individuals in class 4 . Furthermore, class 4 was distinguished by greater prevalence of chronic physical illnesses. The fact that class 4 consisted mainly of individuals aged 45 years and over may explain both the greater number of chronic physical illnesses in this group and greater numbers of individuals with a family physician, as well their higher frequency of visits to a general practitioner.

\section{Limitations}

Some limitations to this study should be considered. First, because this was a cluster analysis, only a limited number of variables could be introduced into the analysis. The selection of other variables (e.g. social support) may have implied different influences on emergency department use, and may have generated different classes of individuals who use emergency departments. Second, intersite variability was not examined. Third, our results may not be generalizable to other samples of emergency department use of individuals with MD-SUD in very different healthcare contexts. Finally, our study was cross-sectional. A longitudinal study could have better highlighted the causal relationships between frequency of emergency department use and the selected needs, predisposing and enabling factors.

This study is, to our knowledge, the first to identify a typology of people who use the emergency department for MD-SUD. Cluster analysis produced four classes, each characterized by specific needs, predisposing and enabling factors, suggesting that some interventions may have more relevance than others when applied to these diverse classes of patients. Concerning individuals with high emergency department and specialized health service use, with multiple MD-SUD' (class 2), assertive community treatment may ensure better continuity of care than usual specialized services as well as reduce the burden of emergency department visits. Other alternatives to emergency department use, such as crisis resolution or home interventions teams, may also be indicated for this group. Concerning 'young, economically disadvantaged males with SUD who made moderately use of emergency departments but little use of other health services' (class 1), the deployment of addiction liaison nurses would be useful for the referral of these patients to addiction rehabilitation centres. Other interventions including motivational interviewing, harm reduction or outreach services may also be effective for encouraging such patients to increase their service use for MD-SUD. Better training of general 
practitioners on SUDs may also increase their level of comfort for treating these people as well as help to reduce stigmatization. For 'older individuals with multiple chronic physical illnesses co-occurring with MDs, who made moderate use of the emergency department, but mainly consulted general practitioners' (class 4), better collaboration could be promoted between primary care and specialized service providers, providing their family physicians with support from psychiatrists and primary care mental health teams (shared-care practice). Finally, for 'middle-aged, economically advantaged females with common MDs, who made moderate use of emergency departments but consulted general practitioners' (class 3), support from the family physician may be enhanced through collaboration with peer support groups.

Marie-Josée Fleury (D, PhD, Department of Psychiatry, McGill University; and Douglas Mental Health University Institute Research Centre, Quebec, Canada; Guy Grenier, PhD, Douglas Mental Health University Institute Research Centre, Quebec, Canada; Jean-Marie Bamvita, MD, PhD, Douglas Mental Health University Institute Research Centre, Quebec, Canada; Francine Ferland, PhD, School of Social Work, Laval University; and Addiction Rehabilitation Centre, University Integrated Health and Social Services Centre - Capitale-Nationale, Quebec, Canada

Correspondence: Marie-Josée Fleury. Email: flemar@douglas.mcgill.ca

First received 6 Aug 2019, final revision 16 Jan 2020, accepted 23 Apr 2020

\section{Data availability}

M.-J.F. and J.-M.B. had full access to all data. M.-J.F. currently has the data and has ongoing access. Selected non-identifiable data are available from M.-J.F. on request.

\section{Acknowledgements}

We would like to thank the funding agency cited above for their support, as well as the individuals who participated in this research and Judith Sabetti for linguistic revision.

\section{Author contributions}

M.-J.F. and F.F. participated in the design of the manuscript and data collection. M.-J.F., G.G. and J.-M.B. wrote the article. J.-M.B. produced the quantitative analyses and tables. F.F. revised the manuscript. All authors approved the final version.

\section{Funding}

This study was funded by the Fonds de la recherche en santé du Québec, grant number 30820.

\section{Declaration of interest}

None

ICMJE forms are in the supplementary material, available online at https://doi.org/10.1192/ bjo.2020.39.

\section{References}

1 Bruffaerts R, Sabbe M, Demyttenaere K. Emergency psychiatry in the 21st century: critical issues for the future. Eur J Emerg Med 2008; 15(5): 276-8.

2 Halmer TC, Beall RC, Shah AA, Dark C. Health policy considerations in treating mental and behavioral health emergencies in the United States. Emerg Med Clin North Am 2015; 33(4): 875-91.

3 Blumstein $\mathrm{H}$, Singleton $\mathrm{AH}$, Suttenfield CW, Hiestand BC. Weekday psychiatry faculty rounds on emergency department psychiatric patients reduces length of stay. Acad Emerg Med 2013; 20(5): 498-502.

4 Aagaard J, Aagaard A, Buus N. Predictors of frequent visits to a psychiatric emergency room: a large-scale register study combined with a small-scale interview study. Int J Nurs Stud 2014; 51(7): 1003-13.

5 Misek RK, DeBarba AE, Brill A. Predictors of psychiatric boarding in the emergency department. West J Emerg Med 2015; 16(1): 71-5.

6 Moreno-Kustner B, Warnke I, Nordt C, Fernandez G, Ramos J, Paulino-Matos P, et al. Predictors of repeat visits to hospital psychiatric emergency departments in Malaga (Spain) and in Lisbon (Portugal). Emerg Med J 2017; 34(10): 665-71.

7 Anderson EL, Nordstrom K, Wilson MP, Peltzer-Jones JM, Zun L, Ng A, et al. American Association for Emergency Psychiatry Task Force on Medical
Clearance of Adults part I: introduction, review and evidence-based guidelines. West J Emerg Med 2017; 18(2): 235-42.

8 Slade M, Taber D, Clarke MM, Johnson C, Kapoor D, Leikin JB, et al. Best practices for the treatment of patients with mental and substance use illnesses in the emergency department. Dis Mon 2007; 53(11-12): 536-80.

9 Eppling J. First encounters: a psychiatric emergency program. J Emerg Nurs 2008; 34(3): 211-7.

10 Abello A J, Brieger B, Dear K, King B, Ziebell C, Ahmed A, et al. Care plan program reduces the number of visits for challenging psychiatric patients in the ED. Am J Emerg Med 2012; 30(7): 1061-7.

11 Pearlmutter MD, Dwyer KH, Burke LG, Rathlev N, Maranda L, Volturo G. Analysis of emergency department length of stay for mental health patients at ten Massachusetts emergency departments. Ann Emerg Med 2017; 70(2): 193202. e16.

12 Stephens RJ, White SE, Cudnik M, Patterson ES. Factors associated with longer length of stay for mental health emergency department patients. J Emerg Med 2014; 47(4): 412-9.

13 Weiss AP, Chang G, Rauch SL, Smallwood JA, Schechter M, Kosowsky J, et al. Patient- and practice-related determinants of emergency department length of stay for patients with psychiatric illness. Ann Emerg Med 2012; 60(2): 162-71. e5

14 Heyland $M$, Johnson $M$. Evaluating an alternative to the emergency department for adults in mental health crisis. Issues Ment Health Nurs 2017; 38(7): 557-61.

15 Althaus F, Paroz S, Hugli O, Ghali WA, Daeppen JB, Peytremann-Bridevaux I, et al. Effectiveness of interventions targeting frequent users of emergency departments: a systematic review. Ann Emerg Med 2011; 58(1): 41-52. e42.

16 Andersen RM. Revisiting the behavioral model and access to medical care: does it matter? J Health Soc Behav 1995; 36(1): 1-10.

17 Gasperini B, Cherubini A, Pierri F, Barbadoro P, Fedecostante M, Prospero E. Potentially preventable visits to the emergency department in older adults: results from a national survey in Italy. PLoS One 2017; 12(12): e0189925.

18 Young AS, Chinman MJ, Cradock-O'Leary JA, Sullivan G, Murata D, Mintz J, et al. Characteristics of individuals with severe mental illness who use emergency services. Community Ment Health J 2005; 41(2): 159-68.

19 Huynh C, Ferland F, Blanchette-Martin N, Menard JM, Fleury MJ. Factors influencing the frequency of emergency department utilization by individuals with substance use disorders. Psychiatr Q 2016; 87(4): 713-28.

20 Fleury MJ, Rochette L, Grenier G, Huynh C, Vasiliadis HM, Pelletier E, et al. Factors associated with emergency department use for mental health reasons among low, moderate and high users. Gen Hosp Psychiatry 2019; 60: 111-9.

21 Hamilton JE, Desai PV, Hoot NR, Gearing RE, Jeong S, Meyer TD, et al. Factors associated with the likelihood of hospitalization following emergency department visits for behavioral health conditions. Acad Emerg Med 2016; 23(11): 1257-66.

22 Chaput YJA, Lebel M-J. Demographic and clinical profiles of patients who make multiple visits to psychiatric emergency services. Psychiatr Serv 2007; 58(3): 335-41.

23 Vu F, Daeppen JB, Hugli O, Iglesias K, Stucki S, Paroz S, et al. Screening of mental health and substance users in frequent users of a general Swiss emergency department. BMC Emerg Med 2015; 15: 27.

24 Wooden MD, Air TM, Schrader GD, Wieland B, Goldney RD. Frequent attenders with mental disorders at a general hospital emergency department. Emerg Med Australas 2009; 21(3): 191-5.

25 Chang G, Weiss AP, Orav EJ, Rauch SL. Predictors of frequent emergency department use among patients with psychiatric illness. Gen Hosp Psychiatry 2014; 36(6): 716-20.

26 Pasic J, Russo J, Roy-Byrne P. High utilizers of psychiatric emergency services. Psychiatr Serv 2005; 56(6): 678-84.

27 Poremski D, Kunjithapatham G, Koh D, Lim XY, Alexander M, Lee C. Lost keys: understanding service providers' impressions of frequent visitors to psychiatric emergency services in Singapore. Psychiatr Serv 2017; 68(4): 390-5.

28 Richard-Lepouriel H, Weber K, Baertschi M, DiGiorgio S, Sarasin F, Canuto A. Predictors of recurrent use of psychiatric emergency services. Psychiatr Serv 2015; 66(5): 521-6.

29 Ledoux $Y$, Minner P. Occasional and frequent repeaters in a psychiatric emergency room. Soc Psychiatry Psychiatr Epidemiol 2006; 41(2): 115-21.

30 Brennan JJ, Chan TC, Hsia RY, Wilson MP, Castillo EM. Emergency department utilization among frequent users with psychiatric visits. Acad Emerg Med 2014; 21(9): 1015-22.

31 Curran GM, Sullivan G, Williams K, Han X, Collins K, Keys J, et al. Emergency department use of persons with comorbid psychiatric and substance abuse disorders. Ann Emerg Med 2003; 41(5): 659-67. 
32 Curran G, Sullivan G, Williams K, Han X, Allee E, Kotrla K. The association of psychiatric comorbidity and use of the emergency department among persons with substance use disorders: an observational cohort study. BMC Emerg Med 2008; 8(1): 17.

33 Brunero S, Fairbrother G, Lee S, Davis M. Clinical characteristics of people with mental health problems who frequently attend an Australian emergency department. Aust Health Rev 2007; 31(3): 462-70.

34 Sirotich F, Durbin A, Durbin J. Examining the need profiles of patients with multiple emergency department visits for mental health reasons: a cross-sectiona study. Soc Psychiatry Psychiatr Epidemiol 2016; 51(5): 777-86.

35 Blonigen DM, Macia KS, Bi X, Suarez P, Manfredi L, Wagner TH. Factors associated with emergency department use among veteran psychiatric patients. Psychiatr Q 2017; 88(4): 721-32.

36 Buhumaid R, Riley J, Sattarian M, Bregman B, Blanchard J. Characteristics of fre quent users of the emergency department with psychiatric conditions. J Health Care Poor Underserved 2015; 26(3): 941-50.

37 Merrick EL, Perloff J, Tompkins CP. Emergency department utilization pattern for Medicare beneficiaries with serious mental disorders. Psychiatr Serv 2010; 61(6): 628-31.

38 Wise-Harris D, Pauly D, Kahan D, de Bibiana J T, Hwang SW, Stergiopoulos V. "Hospital was the only option": experiences of frequent emergency department users in mental health. Adm Policy Ment Health 2017; 44(3): 405-12.

39 Cederbaum JA, Guerrero EG, Mitchell KR, Kim T. Utilization of emergency and hospital services among individuals in substance abuse treatment. Subst Abuse Treat Prev Policy 2014; 9: 16.

40 Arfken CL, Zeman LL, Yeager L, White A, Mischel E, Amirsadri A. Case-contro study of frequent visitors to an urban psychiatric emergency service. Psychiatr Serv 2004; 55(3): 295-301

41 Ayangbayi $\mathrm{T}$, Okunade $\mathrm{A}$, Karakus $\mathrm{M}$, Nianogo $\mathrm{T}$. Characteristics of hospita emergency room visits for mental and substance use disorders. Psychiat Serv 2017; 68(4): 408-10.

42 Kahan D, Leszcz M, O'Campo P, Hwang SW, Wasylenki DA, Kurdyak P, et al Integrating care for frequent users of emergency departments: implementation evaluation of a brief multi-organizational intensive case management intervention. BMC Health Serv Res 2016; 16: 156

43 Nesper AC, Morris BA, Scher LM, Holmes JF. Effect of decreasing county menta health services on the emergency department. Ann Emerg Med 2016; 67(4): 525-30.

44 Herman SE, Mowbray CT. Client typology based on functioning level assessments: utility for service planning and monitoring. J Ment Health Adm 1991 18(2): 101-15

45 Guzzetta F, Miglio R, Santone G, Picardi A, Norcio B, Bracco R, et al. First-ever admitted psychiatric inpatients in Italy: clinical characteristics and reasons contributing to admission: findings from a national survey. Psychiatry Res 2010; 176(1): $62-8$.

46 Fisher S, Stevens RF. Subgroups of frequent users of an inpatient mental health program at a community hospital in Canada. Psychiatr Serv 1999; 50(2): 244-7.

47 Rocca P, Montemagni C, Mingrone C, Crivelli B, Sigaudo M, Bogetto F. A clusteranalytical approach toward real-world outcome in outpatients with stable schizophrenia. Eur Psychiatry 2016; 32: 48-54.

48 Huynh C, Tremblay J, Fleury MJ. Typologies of individuals attending an addiction rehabilitation center based on diagnosis of mental disorders. J Subst Abuse Treat 2016; 71: 68-78.

49 Fleury MJ, Grenier G, Bamvita JM, Piat M, Tremblay J. Adequacy of help received among individuals with severe mental disorders. Adm Policy Ment Health 2014; 41(3): 302-16

50 Perreault M, Toure el H, Fleury MJ, Beaulieu S, Caron J. Development of a typology of antidepressant users: the role of mental health disorders and substance use. J Popul Ther Clin Pharmacol 2016; 23(1): e90-102.
51 Gentil L, Grenier G, Bamvita JM, Dorvil H, Fleury MJ. Profiles of quality of life in a homeless population. Front Psychiatry 2019; 10: 10

52 Ministry of Health and Social Services. Bill 10, An Act to modify the organization and governance of the health and social services network, in particular by abolishing the regional agencies. Government of Quebec, 2015.

53 Bohn MJ, Babor TF, Kranzler HR. The Alcohol Use Disorders Identification Test (AUDIT): validation of a screening instrument for use in medical settings. $J$ Stud Alcohol Drugs 1995; 56(4): 423-32.

54 Carey KB, Carey MP, Chandra PS. Psychometric evaluation of the alcohol use disorders identification test and short drug abuse screening test with psychiatric patients in India. J Clin Psychiatry 2003; 64(7): 767-74.

55 Kisely S, Asbridge M, Connor J, White A, Pais J, Lin E. Using administrative health data for the surveillance of interventions for alcohol-related harm among young people. CMAJ 2012; 184(1): 49-53.

56 Vandyk $A D$, Harrison $M B$, VanDenKerkhof EG, Graham ID, Ross-White $A$ Frequent emergency department use by individuals seeking mental healthcare: a systematic search and review. Arch Psychiatr Nurs 2013; 27(4): 171-8.

57 Fleury MJ, Fortin M, Rochette L, Grenier G, Huynh C, Pelletier E, et al. Assessing quality indicators related to mental health emergency room utilization. $B M C$ Emerg Med 2019; 19(1): 8 .

58 Fleury MJ, Grenier G, Bamvita JM, Perreault M, Caron J. Typology of adults diag nosed with mental disorders based on socio-demographics and clinical and service use characteristics. BMC Psychiatry 2011; 11: 67.

59 Mehl-Madrona LE. Prevalence of psychiatric diagnoses among frequent users of rural emergency medical services. Can J Rural Med 2008; 13(1): 22-30.

60 Doran KM, Raven MC, Rosenheck RA. What drives frequent emergency department use in an integrated health system? National data from the Veterans Health Administration. Ann Emerg Med 2013; 62(2): 151-9.

61 Saillant S, Hudelson P, Dominice Dao M, Junod Perron N. The primary care physician/psychiatrist joint consultation: A paradigm shift in caring for patients with mental health problems? Patient Educ Couns 2016; 99(2): 279-83.

62 Koivunen M, Harju S, Kauko T, Valimaki M. Alcohol risk drinking, quality of life and health state among patients treated at the sobering unit in the emergency department - one year follow-up study. Int Emerg Nurs 2017; 31: 22-9.

63 Levinson D, Rosca P, Vilner D, Brimberg I, Stall Y, Rimon A. Binge drinking among young adults in an urban tertiary care emergency department in Israel. Isr J Health Policy Res 2017; 6(1): 34.

64 Urbanoski KA, Rush BR, Wild TC, Bassani DG, Castel S. Use of mental health care services by Canadians with co-occurring substance dependence and mental disorders. Psychiatr Serv 2007; 58(7): 962-9.

65 Verduin ML, Carter RE, Brady KT, Myrick H, Timmerman MA. Health service use among persons with comorbid bipolar and substance use disorders. Psychiatr Serv 2005; 56(4): 475-80.

66 Schomerus G, Lucht M, Holzinger A, Matschinger H, Carta MG, Angermeyer MC. The stigma of alcohol dependence compared with other mental disorders: a review of population studies. Alcohol Alcohol 2011; 46(2): 105-12.

67 Moller-Leimkuhler AM. Barriers to help-seeking by men: a review of sociocultural and clinical literature with particular reference to depression. J Affect Disord 2002; 71(1-3): 1-9.

68 Hermann RC, Mattke S, Somekh D, Silfverhielm $\mathrm{H}$, Goldner $\mathrm{E}$, Glover G, et al. Quality indicators for international benchmarking of mental health care. Int J Qual Health Care 2006; 18(Suppl 1): 31-8. 